\title{
REKAYASA SISTEM KOMPUTER SEBAGAI ALAT BANTU AJAR BERDASARKAN TEORI KONSTRUKTIVISTIK
}

\author{
(Computer System Engineering as Teaching Aid Based on \\ Constructivistics Theory)
}

\author{
April Firman Daru \\ Fakultas Teknologi Informasi dan Komunikasi Universitas Semarang
}

\begin{abstract}
Learning pattern that is happening now tends to be monoactive. The instructors become very dominant in learning process, while the students are treated as an object which has to be fed. Some courses that relate to practical subject involve in this kind of problem. It becomes more complicated by the lack of practical facilities and infrastructures. For some courses that purpose to sharpen the students' skill, needed an interactive learning process focusing on practice which is done frequently. Learning process that is done only in learning hours is not sufficient to make the student comprehens the material well. Therefore it is needed to do computer system engineering by an effective learning analysis based on constructivistics theory approach so that it can be obtained teaching aid which functions as a supplement in learning process. The use of multimedia as a media instructional in learning can be an alternative to overcome the problem.
\end{abstract}

Keyword : learning, computer, Constructivistics

\section{PENDAHULUAN}

Proses belajar mengajar yang terjadi saat ini masih cenderung dalam pola yang searah atau monoaktif, dimana peran pengajar lebih mendominasi proses pembelajaran. Siswa cenderung dipandang sebagai obyek dengan kemampuan yang sama sehingga kemajemukan potensi siswa tidak terakomodasi dalam proses pembelajaran. Dalam perjalanannya terdapat banyak kendala untuk mencapai hasil yang baik, salah satu faktor kegagalan pembelajaran adalah adanya berbagai jenis hambatan dalam proses komunikasi antar siswa dan pengajar. Berbagai jenis hambatan itu, baik yang berasal dari pengajar maupun siswa, membuat komunikasi belajar mengajar tidak berjalan secara efektif dan efesien.

Proses belajar konstruktivistik memandang bahwa proses belajar lebih bertumpu pada keaktifan siswa untuk memperoleh pengetahuan. Proses belajar ini bersifat interaktif dimana siswa melakukan kegiatan, aktif berfikir, menyusun konsep dan memberi makna tentang hal-hal yang sedang dipelajari.

Kendali proses pada model belajar ini berada pada siswa. Guru bertindak sebagai fasilitator agar proses belajar dapat berlangsung secara optimal. Untuk mendukung model pembelajaran konstruktivistik dibutuhkan sarana pembelajaran interaktif. Salah satunya pembelajaran berbasis komputer.

Untuk mengukur tingkat pemahaman peserta ajar terhadap penguasaan materi dibutuhkan evaluasi. Model evaluasi yang dipakai pun bermacam-macam, salah satu diantaranya model evaluasi yang dilengkapi dengan simulasi berbasis komputer. Model ini lebih bermanfaat bila digunakan pada mata kuliah praktikum, karena pada mata kuliah praktikum, pemahaman peserta ajar bukan hanya sebatas kognitif namun juga keahlian sehingga dibutuhkan proses belajar interaktif 
yang menuntut siswa aktif saat proses pembelajaran. Dengan keterbatasan sarana, waktu, ruang dan pengajar maka model pembelajaran kontruktivistik dengan bantuan komputer diharapkan mampu menjadi sarana menuju proses belajar interaktif.

\section{TINJAUAN PUSTAKA}

\subsection{Pembelajaran}

Menurut Khalid Mohamad Nor pembelajaran merupakan kegiatan yang bergantung kepada akal. Baharuddun Aris, et al., juga menyatakan pembelajaran adalah perubahan tingkah laku yang berlaku pada pelajar akibat dari berinteraksi dengan lingkungan. Secara umum pembelajaran diartikan sebagai proses dengan kaedahkaedah tertentu sehingga orang memperoleh pengetahuan, pemahaman dan cara bertingkah laku yang sesuai dengan keperluan.

Pemberian kebebasan kepada siswa merupakan pilihan yang sangat tepat dan diinginkan untuk memperdayakan pengalaman belajar siswa secam lebih lanjut Sheal, Peter menuliskan "Pencapaian pengalaman belajar $10 \%$ dari apa yang kita baca, 20\% dari apa yang kita dengar, 30\% dari apa yang kita lihat, $50 \%$ dan apa yang kita lihat dan dengar, 70\% dari apa yang kita katakan, dan $90 \%$ dari apa yang kita katakan dan lakukan".

Jeannette Von, Gordon Dryden" kita belajar melihat apa yang kita lihat, apa yang kita dengar, apa yang kita kecap, apa yang kita sentuh, apa yang kita baui, apa yang kita lakukan, apa yang kita bayangkan, apa yang kita intuisasikan dan apa yang kita rasakan".

Teknologi pemebelajaran sebagai proses pemecahan masalah belajar dan sistem berpikir merupakan bidang yang sangat diperlukan untuk meningkatkan kualitas pendidikan dan pembelajaran, baik di lembaga pendidikan formal maupun non formal, dalam sistem akademik maupun lembaga pelatihan. Dengan kekuatannya pendekatan sistem , pembelajaran yang dirancang menggunakan teori dan model rancangan pembelajaran, menjanjikan belajar menjadi lebih efektif, lebih efesien, dan lebih menarik. Melalui teknologi pembelajaran kegiatan pendidikan dan pelatihan akan "more knowledgeable, more skillfull, more confident, more independent, more empathetic, and more rational"

\subsection{Teori Konstruktivistik}

Pembelajaran konstruktivistik adalah suatu proses pembelajaran yang mengkondisikan siswa untuk melakukan proses aktif membangun konsep-konsep baru, pengertianpengertian baru, pengetahuan-pengetahuan baru beradasarkan data, informasi, dan pengetahuan yang dimiliki sebelumnya. Proses tersebut akan efektif jika siswa mampu secara kreatif merancang tujuan belajar dan memiliki concern yang kuat terhadap proses belajar (Clough dan Clark, 1994). Agar memiliki makna, belajar harus terjadi dalam latar yang aktual dan diacukan ke arah pemecahan masalah aktual yang diahadapi siswa dalam kehidupan sehari-hari. Pentingnya kebermaknaan dalam proses belajar juga ditegaskan oleh Gagne (1985) dan Marzano (1992).

Salah satu teori atau pandangan yang sangat terkenal berkaitan dengan teori belajar konstruktivistik adalah teori perkembangan mental Piaget. Teori ini biasa disebut teori perkembangan intelektual atau teori perkembangan kognitif. Teori belajar tersebut berkenaan dengan kesiapan siswa untuk belajar, yang dikemas dalam tahap perkembangan intelektual dari lahir hingga dewasa. Setiap tahap perkembangan intelektual yang dimaksud dilengkapi dengan ciri-ciri tertentu dalam mengkonstruksi ilmu pengetahuan.

Pembelajaran konstruktivistik adalah suatu proses pembelajaran yang mengkondisikan siswa untuk melakukan proses aktif membangun konsep-konsep baru, pengertianpengertian baru, pengetahuan-pengetahuan baru beradasarkan data, informasi, dan pengetahuan yang dimiliki sebelumnya. Proses tersebut akan efektif jika siswa mampu secara kreatif merancang tujuan belajar dan 
memiliki concern yang kuat terhadap proses belajar (Clough dan Clark, 1994). Agar memiliki makna, belajar harus terjadi dalam latar yang aktual dan diacukan ke arah pemecahan masalah aktual yang diahadapi siswa dalam kehidupan sehari-hari. Pentingnya kebermaknaan dalam proses belajar juga ditegaskan oleh Gagne (1985) dan Marzano (1992).

Menurut teori belajar konstruktivistik, pengetahuan tidak dapat dipindahkan begitu saja dari pikiran guru ke pikiran siswa. artinya bahwa siswa harus aktif secara mental membangun struktur pengetahuannya berdasarkan kematangan kognitif yang dimilikinya.

Pengertian pendekatan konstruktivisme adalah pendekatan yang mengajak siswa untuk berpikir dan mengkonstruksi dalam memecahkan suatu permasalahan secara bersama-sama sehingga didapatkan suatu penyelesaian yang akurat.

Tiga penekanan dalam teori belajar dengan pendekatan konstruktivisme sebagai berikut: peran aktif siswa dalam mengkonstruksi pengetahuan secara bermakna, pentingnya membuat kaitan antara gagasan dalam mengkonstruksian pengetahuan tersebut dan mengaitkan antara gagasan dengan informasi baru yang diterima.

Dari prinsip utama dalam pembelajaran dengan metode pendekatan belajar konstruktivistik adalah pengetahuan tidak dapat diperoleh secara pasif, tetapi secara aktif oleh struktur kognitif siswa dan fungsi kognitif bersifat adatif dan membantu pengorganisasian melalui pengalaman nyata yang dimiliki siswa.

Kegiatan mengajar idealnya mampu memberikan pengalaman baru dan pencerahan pada siswa sehingga mereka mengalami 'ketagihan' untuk belajar sendiri secara lebih mendalam. Konstruktivisme memandang penting peran siswa untuk dapat membangun constructive habits of mind dalam diri masing-masing siswa melalui setiap proses pembelajaran (Driver dan Leach, 1993). Pembelajaran konstruktivistik memiliki beberapa varian, diantaranya discovery learning, scaffolding learning, cooperative learning, problem based instruction (Slavin, 1994; Arends, 1997)

\subsection{Multimedia}

Multimedia mengacu kepada proses komunikasi interaktif berasaskan komputer yang mencakup penggunaan teks, grafik, audio, video dan animasi. Hasil dari penggunaan berbagai media ini menghasilkan sesuatu pernyataan bahwa menggunakan teknologi Multimedia kelihatan lebih hidup, dinamik dan mampu menarik perhatian bagi pengguna.

Daya ingatan seseorang dapat menyimpan hanya:
a. $20 \%$ dari apa yang dibaca
b. $30 \%$ dari apa yang didengar
c. $40 \%$ dari apa yang dilihat
d. $50 \%$ dari apa yang disebut
e. $60 \%$ dari apa yang dibuat
f. $90 \%$ dari apa yang dibaca, didengar,dilihat, disebut dan dibuat secara bersamaan

Penggunaan Multimedia dapat memenuhi ciri yang keenam yaitu daya ingatan seseorang dapat menyimpan sampai $90 \%$. Hal ini dikarenakan Multimedia mempunyai elemen-elemen teks, grafik, video, audio dan animasi yang dapat diaplikasikan secara bersama-sama.

\subsection{E-Learning}

Istilah e-Learning mengandung pengertian yang sangat luas, sehingga banyak pakar yang menguraikan tentang definisi e-Learning dari berbagai sudut pandang. Salah satu definisi yang cukup dapat diterima banyak pihak misalnya dari Darin E. Hartley [Hartley, 2001] yang menyatakan: e-Learning merupakan suatu jenis belajar mengajar yang memungkinkan tersampaikannya bahan ajar ke siswa dengan menggunakan media Internet, Intranet atau media jaringan komputer lain. 
LearnFrame.Com dalam Glossary of eLearning Terms [Glossary, 2001] menyatakan suatu definisi yang lebih luas bahwa: eLearning adalah sistem pendidikan yang menggunakan aplikasi elektronik untuk mendukung belajar mengajar dengan media Internet, jaringan komputer, maupun komputer standalone.

Pengertian e-learning yang sederhana namun mengena dikatakan oleh Maryati S.Pd., e-learning terdiri dari dua bagian yaitu e- yang merupakan singkatan dari elektronika dan learning yang berarti pembelajaran. Jadi elearning berarti pembelajaran dengan menggunakan jasa bantuan perangkat elektronika, khususnya perangkat komputer. Terdapat kata "khususnya komputer" pada akhir kalimat yang member pengertian bahwa komputer termasuk alat elektronik disamping alat pembelajaran elektronik yang lain.

Jika dilihat dari berbagai pengertian elearning, kebanyakan dari para pakar mengatakan bahwa e-learning merupakan pembelajaran menggunakan sarana internet. Namun jika dilihat dari arti harfiah bahwa elearning yang mempunyai kepanjangan electronic-learning berarti pembelajaran yang menggunakan sarana elektronik. Disini, sarana elektronik ada berbagai macam, radio, tape audio/video, tv interaktif, cdrom, seperangkat komputer, LCD Proyektor, OHP.

Komputer termasuk didalam alat elektronik, namun dalam hal ini, komputer masih digunakan untuk menyiapkan bahan presentasi dosen dan untuk pengajaran interaktif menggunakan CD-ROM maupun untuk membantu presentasi dosen di ruang kelas. Komputer di sini masih berdiri sendiri (stand alone) dan belum tersamung ke internet. Sehingga komputer disini termasuk media pembelajaran elektronik. Sehingga tepat jika komputer sebagai salah satu media pembelajaran e-learning.

\subsection{Rekayasa Sistem Pembelajaran}

Dalam bentuk diagram, rekayasa sistem merupakan bagian sistem yang lebih besar (suprasistem). Setiap subsistem, misalnya subsistem Analisis, dapat terdiri dari subsistem Pengembangan Perangkat Identifikasi Kebutuhan dan Pengembangan Tujuan Pembelajaran. Subsistem Pengembangan Tujuan Pembelajaran dapat memiliki subsistem Pengembangan Tujuan Kognitif yang meliputi Analisis Tujuan Kognitif, Desain Tujuan Kognitif, dst.

- Menurut de Lisle, proses rekayasa sistem memiliki tahap : Analysis, Design, Development, Implementation, and Evaluation.

- Sedangkan menurut Davis, terdiri dari : Problem Definition, Feasibility Study, Analysis, System Design, Detailed Design, Implementation, Maintenance.

- Whitten berpendapat bahwa rekayasa sistem meliputi proses : Systems Analysis, Systems Design, dan Systems Implementation.

Sedangkan menurut Scott terdiri dari : Preliminary Study, Systems Analysis, Systems Design, dan Implementation.

\section{METODE}

Metode yang dipakai untuk mengembangkan adalah rekayasa (Reengineering), yaitu suatu kegiatan merancang (design) yang tidak rutin, sehingga di dalamnya terdapat kontribusi baru, baik dalam bentuk, proses maupun produk.

Tahap tahap pengembangan sistemnya adalah sebagai berikut :

a. Tahap 1. Persiapan awal Pembuatan Alat Bantu Ajar adalah menelaah konsepkonsep utama dalam sub pokok bahasan atau pokok bahasan materi .

b. Tahap 2. Pembuatan Alat Bantu Ajar

1. Membuat draft isi Alat bantu Ajar.

2. Merancang dan mengembangkan Alat Bantu Ajar dalam hal ini animasi dan Sistem komputer interaktif sesuai dengan silabus.

3. Menyatukankan semua komponen dalam sistem agar menjadi satu kesatuan.

4. Melakukan penyimpanan dalam bentuk DVD Pembelajaran. 
c. Tahap 3. Implementasi

DVD pembelajaran yang sudah jadi diuji sehingga dapat diketahui kelebihan dan kekuarangannya untuk dapat ditindak lanjuti.

d. Tahap 4. Evaluasi

Evaluasi dilakukan agar kekurangan Alat Bantu Ajar yang telah diuji coba dapat diperbaiki dan terus disempurnakan.

\section{Pembahasan}

Model pembelajaran memiliki tahapan proses pembelajaran yang mengkondisikan siswa untuk melakukan proses aktif membangun konsep-konsep baru, pengertianpengertian baru, pengetahuan-pengetahuan baru beradasarkan data, informasi, dan pengetahuan yang dimiliki sebelumnya.

1. Proses belajar mengajar yang terjadi saat ini masih cenderung dalam pola yang searah atau monoaktif, dimana peran pengajar lebih mendominasi proses pembelajaran.

2. Siswa cenderung dipandang sebagai obyek dengan kemampuan yang sama sehingga kemajemukan potensi siswa tidak terakomodasi dalam proses pembelajaran.

3. Model pembelajaran dengan metode e-learning perlu dilengkapi sarana yang mendukung proses pembelajaran praktikum.

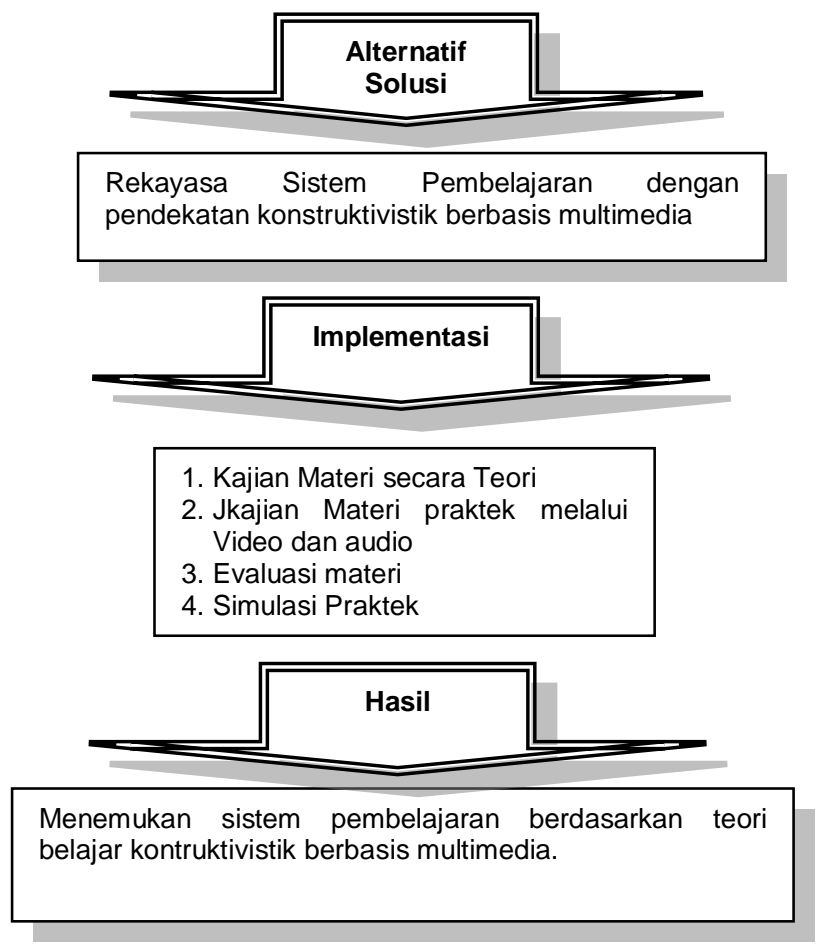

Gambar 1. Kerangka Berpikir

\subsection{Tahapan Proses Pembelajaran}

1. Menjelaskan materi Pengenalan System meliputi bagian-bagian penting dan hardware yang ada pada PC dalam bentuk tutorial. 


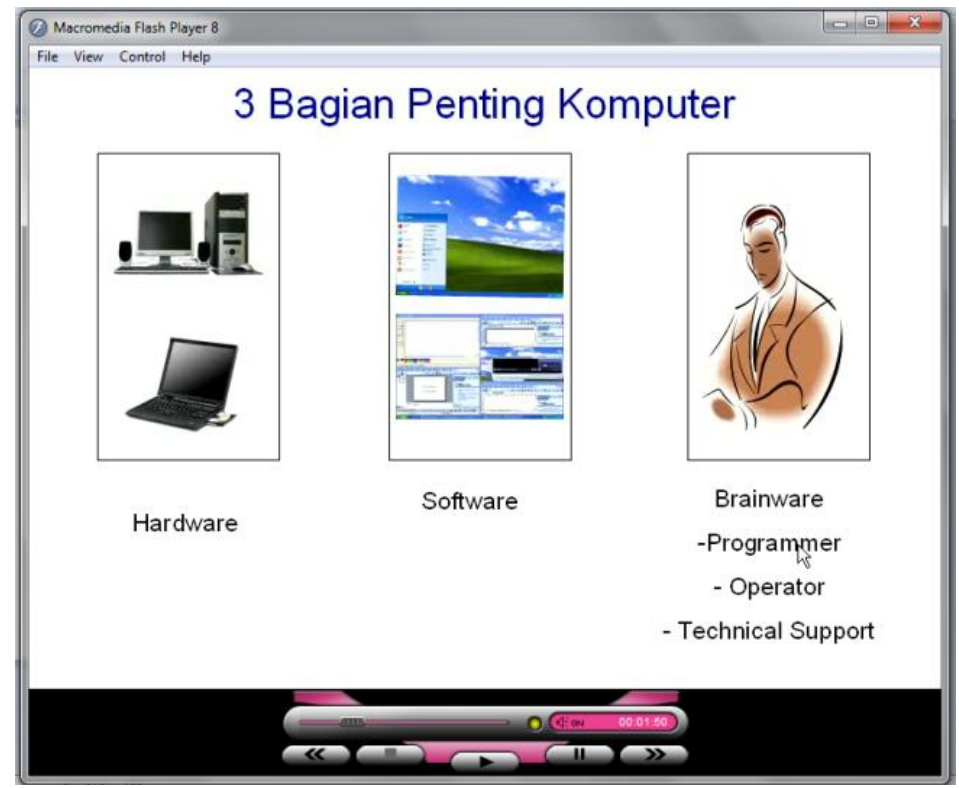

Gambar 2. Penjelasan Materi

2. Setelah mempelajari materi maka dilanjutkan dengan praktek secara (hardware) yang ada didalam PC virtual, mempelajaril bagian-bagian berbentuk Video.

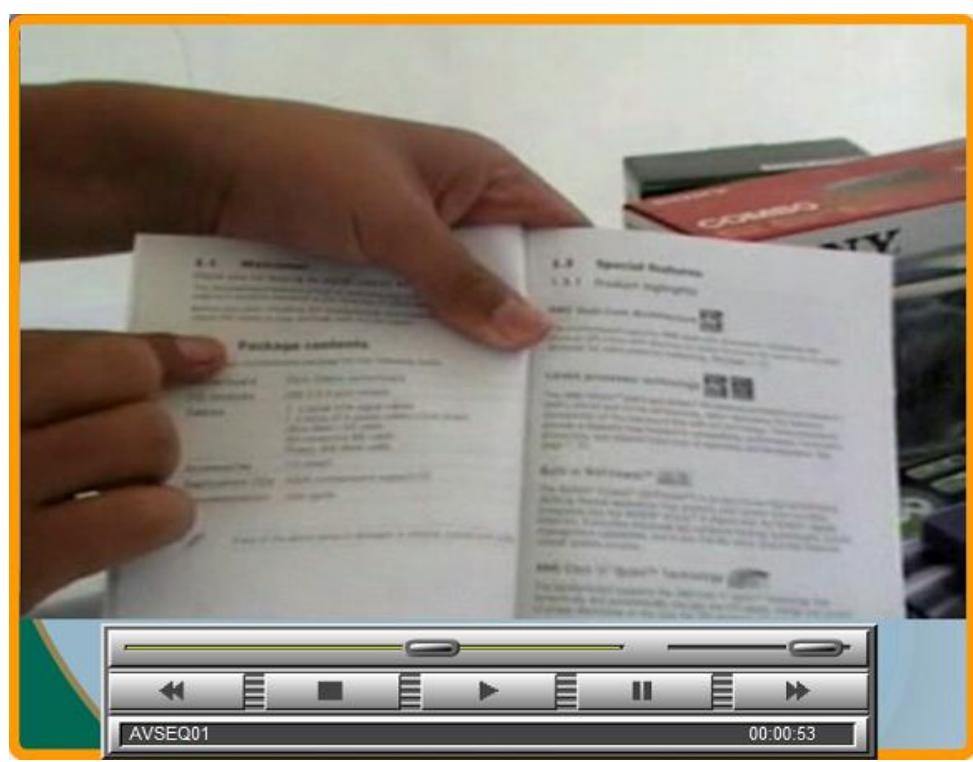

Gambar 3. Video Materi

3. Tahap selanjutnya adalah dengan tingkat pemahaman siswa tentang melakukan evaluasi untuk mengukur materi yang telah dipelajari. 


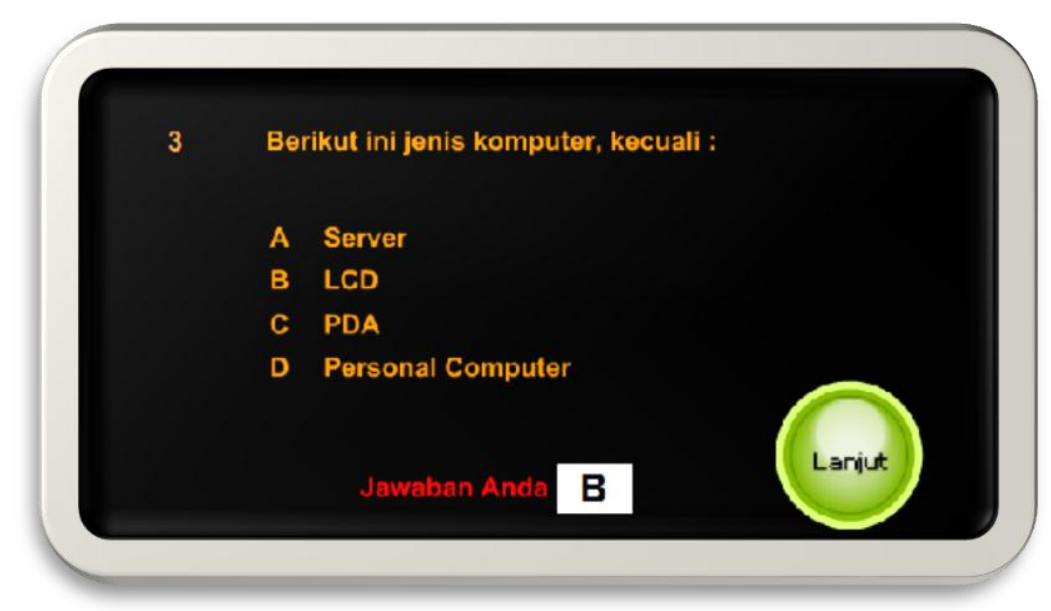

Gambar 4. Evaluasi

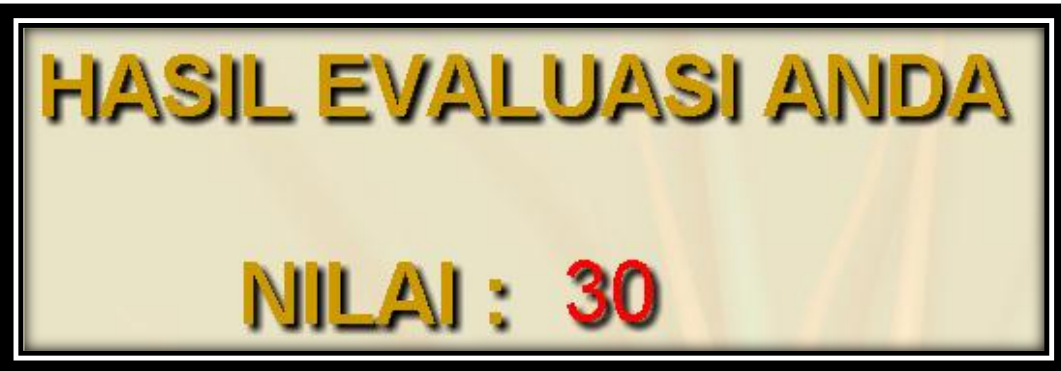

Gambar 5. Hasil Evaluasi

4. Setelah melakukan evaluasi yang merupakan pengujian secara kognitif, maka dilanjutkan dengan melakukan

simulasi untuk mengevaluasi
mahasiswa setelah dbelajar
praktikum secara visual.

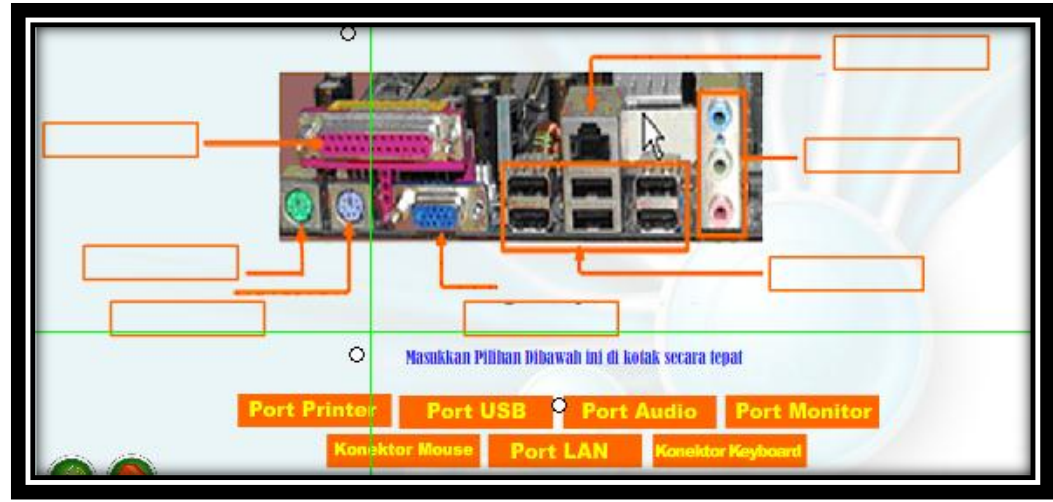

Gambar 6. Test Simulasi 


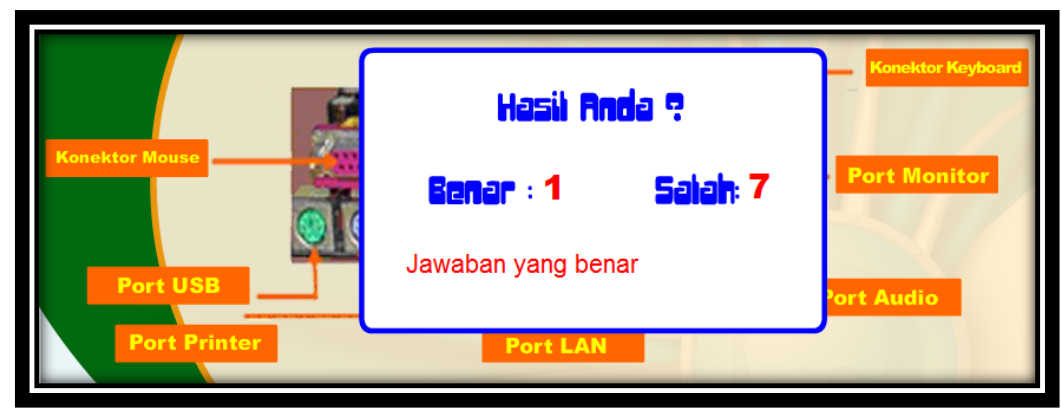

Gambar 7. Hasil Simulasi

\section{KESIMPULAN}

Metode pendekatan belajar konstruktivistik adalah metode dimana pengetahuan tidak dapat diperoleh secara pasif, tetapi secara aktif oleh struktur kognitif siswa. Fungsi kognitif bersifat adaptif dan membantu pengorganisasian melalui pengalaman nyata yang dimiliki siswa.

Dengan menggunakan media pembelajaran multimedia berbasis komputer, proses pembelajaran dapat dilakukan lebih leluasa tanpa dibatasi jam dan ruang kuliah. Siswa dapat belajar secara mandiri untuk mendapatkan pengetahuan yang sesuai dengan tujuan materi. Hal ini selaras dengan model pembelajaran konstruktivistik, dimana siswa menjalani proses belajar aktif.

Dengan keterbatasan sarana, waktu, ruang dan pengajar, maka model pembelajaran kontruktivistik dengan bantuan komputer mampu menjadi sarana menuju proses belajar interaktif dimana kendali belajar bukan berada pada guru tetapis kepada siswa. Siswa dapat melakukan proses belajar mandiri dimulai dari pemahaman materi sampai dengan evaluasi. http://www.umich.edu/ ed626/define.html pada , diakses pada tanggal 5 February 2008.

Direktorat Jendral Manajemen Pendidikan Dasar dan Menengah (2006). Penembangan Model Pembelajaran yang Efektif, Departemen Pendidikan Nasional. Nurhadi (2006), Aplikasi Multimedia pada Media Pembelajaran Pengenalan Huruf dan Angka dengan Teknik Animasi. Tesis Magister Komputer Universitas Dian Nuswantoro.

Wahono, Romi Satria. (2003). Pengantar eLearning dan pengembangannya, diakses pada alamat http://www.ilmukomputer.com, diakses pada tanggal 20 Januari 2008.

\section{DAFTAR PUSTAKA}

Adri, Muhammad. (2008). Strategi Pengembangan Multimedia Intructional Design , diakses pada alamat http://www.ilmukomputer.com, diakses pada tanggal 30 Januari 2008.

ARL. (2007). Definition of Instructional Design, Applied Research Laboratory, Penn State University, diakses pada alamat 